\title{
Application of DG in Power System Planning and Design
}

\author{
J.Moharana, A.K. Baliarsingh, N.R. Samal, K.C. Meher, M. Mantri, D. Mishra \\ 1.: Lecturer, Indus College of Engg.,Odisha,India \\ 2,3,4,5,6 : Faculty members of Orissa Engineering College,Odisha,India
}

\begin{abstract}
Electricity demand is growing the fastest of all the energy consumed worldwide. The increase in use of electricity is closely linked to the development of countries. It is a trend which is almost certain to continue into the future. This trend has increased the importance of electricity networks and how they are operated and planned. Traditionally, electricity systems have been run by vertically integrated utilities with the focus on the engineering aspects rather than Economic issues. This usually led to a high quality of supply for the consumer but perhaps at the expenses of the cost effectiveness.

In this paper different dynamic issue regarding stability of system has been taken care of basic focus is on system study by analyzing IEEE 30 bus system for optimization of voltage profile of system by using Distributed generation.

\section{General Terms}

Different technique has been used for setting voltage profile in different bus with different load level such as Neutron-raption method, Genetic Algorithm, particle swarm optimization etc et. al.
\end{abstract}

Keywords: - LFS, ELD, DG, GA, PSO.

\section{INTRODUCTION}

Electrical demand is growing the fastest of all the energy consumed worldwide. The increase in use of electricity is closely linked to the development of countries. It is a trend which is almost certain to continue into the future. This trend has increased the importance of electrical networks and how they are operated and planned. Traditionally, electricity system have been run by vertically integrated utilities with the focus on the engineering aspect rather than economic issues. This usually led to a high quality of supply for the consumer but perhaps at the expenses of the cost effectiveness. Distributed generation appears especially attractive to policymaker and regulators because it provides the option of reducing investment in transmission and distribution system and also the option of minimizing the transmission and distribution energy loss.

The power flow or load flow is widely used in power system analysis. It plays a major role in planning the future expansion of the power system. The network load flow solution techniques are used for steady state and dynamic analysis programs.

\section{LOAD FLOW STUDY}

The solution of load flow predicts the state of an electrical network when it is subject to a specified loading condition. The result of the power flow is the voltage magnitude and the angle at each of the system nodes. The bus admittance matrix which is denoted as $\mathrm{Y}$ whose dimension is $(\mathrm{n} \mathrm{x} n)$, where $\mathrm{n}$ is the number of bus in the system. A typical element $Y_{\mathrm{ij}}$ i.e. the bus admittance matrix between node $\mathrm{i}$ and $\mathrm{j}$.

$$
\begin{aligned}
Y_{l j} & =\left|Y_{i j}\right| \angle \theta_{i j} \\
& =\left|Y_{i j}\right| \cos \theta_{l j}+j\left|Y_{i j}\right| \sin \theta_{l j} \\
& =G_{l j}+j B_{l j}
\end{aligned}
$$

\subsection{COMPUTATION OF LINE FLOWS:}

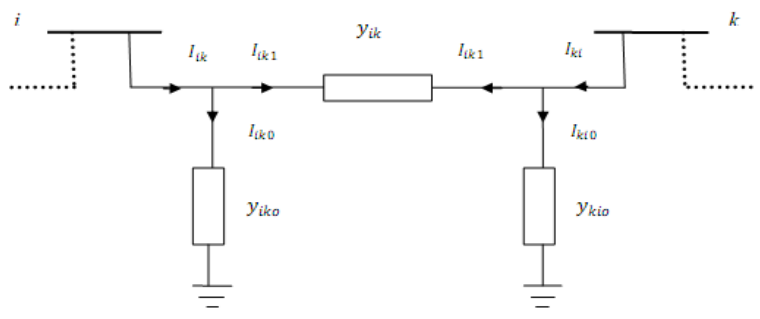

Fig-1. Transmission line connecting i\& $\mathrm{k}$ bus 
Where,

yik=series admittance

yiko, ykio= shunt admittance

Sik= power injected into the line from the $i^{\text {th }}$ bus

$\mathrm{I}^{\mathrm{ik}}=$ current injected by the $\mathrm{i}^{\text {th }}$ bus

$\mathrm{V}_{\mathrm{i}}=$ voltage at the $\mathrm{i}^{\text {th }}$ bus

COMPUTATION OF SLACK BUS POWER:

1. Active power on slack bus can be written as, $\mathrm{P}^{\mathrm{cal}}=\sum_{k=1}^{n}\left|\mathrm{v}_{1} \mathrm{v}_{\mathrm{k}} \mathrm{y}_{\mathrm{lk}}\right| \cos \left(\delta_{1}-\delta_{\mathrm{k}}-\theta_{1 \mathrm{k}}\right)$

2. Reactive power on slack bus is given by, $\mathrm{P}^{\mathrm{cal}}=\sum_{k=1}^{n}\left|\mathrm{v}_{1} \mathrm{v}_{\mathrm{k}} \mathrm{y}_{1 \mathrm{k}}\right| \sin \left(\delta_{1}-\delta_{\mathrm{k}}-\theta_{1 \mathrm{k}}\right)$

\section{LIMITS ON THE VOLTAGE MAGNITUDE $\left(\mathrm{V}_{\mathrm{i}}\right)$}

Power system equipments aredesigned to operate at fixed voltages with allowable variations of $\pm 5 \%$ of the rated value.

\section{ECONOMIC LOAD DISPATCH}

Economic load dispatch is the name given to a process of sharing the total load on a power system between various generating plants to achieve greatest economy operation.

Let us assume, there are $\mathrm{N}$ generators committed and the active power load demand Pdis given, the real power generation $\mathrm{P}_{\mathrm{GI}}$ for each generator has to be allocated so as to minimize the total generation cost.

The total generation cost can therefore be stated as:

$$
\mathrm{F}=\sum_{l=1}^{n} F i\left(\mathrm{P}_{\mathrm{Gi}}\right.
$$

Where,

Where,

$\mathrm{Fi}\left(\mathrm{P}_{\mathrm{Gl}}\right)$ is the operating fuel cost of the $\mathrm{I}^{\text {th }}$ plant and is given by the quadratic equation

$\mathrm{Fi}\left(\mathrm{P}_{\mathrm{Gi}}\right)=\mathrm{a}_{\mathrm{I}} \mathrm{p}_{\mathrm{Gi}}^{2}+\mathrm{b}_{\mathrm{i}} \mathrm{p}_{\mathrm{Gi}}+\mathrm{c}_{\mathrm{i}} \mathrm{Rs} / \mathrm{hr}$

ai, bi, ci are the cost coefficients.

\subsection{SYSTEM CONSTRAINTS:}

Broadly speaking there are two types of constraints:

1. Equality constraints

2. Inequality constraints

\subsection{EQUALITY CONSTRAINTS:}

From observation we can conclude that the cost function is not affected by the reactive power demand. So the full attention is given to the real power balance in the system. Power balance requires that the controlled generation variables $\mathrm{P}_{\mathrm{Gi}}$ obey the constraint equations.

1. Economic Load Dispatch without loss, $\mathrm{P}_{\mathrm{d}}=\sum_{i=0}^{n} P_{\mathrm{Gi}}$

2. $\quad$ Economic Load Dispatch with loss, $\mathrm{P}_{\mathrm{d}}=\sum_{i=0}^{n} P_{\mathrm{Gi}-\mathrm{Pl}}$

\subsection{INEQUALITY CONSTRAINTS:}

The inequality constraints are of different types depending on various factors and these are explained below:

\section{I.GENERATOR CONSTRAINTS}

The maximum active power generation of a source is limited again by thermal consideration and also minimum power generation is limited by the flame instability of a boiler.

$$
\mathrm{P}_{\min } \leq \mathrm{P} \leq \mathrm{P}_{\max }
$$

Similarly, the maximum and minimum reactive power generation of a source is limited,. The maximum reactive power is limited because of overheating of rotor and minimum is limited because of the stability limit of machine. $\quad \mathrm{Q}_{\min } \leq \mathrm{Q} \leq \mathrm{Q}_{\max }$

II. VOLTAGE CONSTRAINTS:

It is essential that the voltage magnitudes at various nodes should vary within certain limits. Usually, $\pm 5 \%$ of base voltage is considered for the upper and lower boundaries i.e. having voltage profile in the range of (0.951.05) p.u.

III. RUNNING SPARE CAPACITY CONSTRAINTS:

The total generation should be such that in addition to meeting load demand and losses a minimum spare capacity should be available i.e. $\mathrm{G} \geq \mathrm{P}+\mathrm{P}_{\text {so }}$

IV. TRANSFORMER TAP SETTING:

If an auto-transformer is used, the minimum tap setting could be zero and the maximum one i.e. $0 \leq \mathrm{t} \leq 1.0$ 
Similarly, for a two winding transformer if tapping are provided on the secondary side, $0 \leq \mathrm{t} \leq \mathrm{n}$

\section{NETWORK SECURITY CONSTRAINTS:}

Initially if a system is operating satisfactorily and there is an outage, may be scheduled or forced one. It is obvious that some of the constraints of the system will be violated. The complexity of these constraints (in terms of number of constraints) is increased when a large system is under study.

\section{DISTRIBUTED GENERATION}

Distributed generation, or DG, includes the application of small generators, typically ranges from $1 \mathrm{kWto}$ $30 \mathrm{MW}$, scattered through a power system, to meet the consumer demands. Whether located on the system, at the site of a consumer, or at an isolated site not connected to the grid.

According to IEEE DEFINITIONS:-

"The Institute of Electrical and Electronics defines Distributed Generation as the generation of electricity by facilities that are sufficiently small to allow interconnection at nearly any point in a power system."

\section{NEW CONCEPT OF POWER SYSTEMS}

In this new conception, the generation is not exclusive to level 1.

Hence some of the energy demand is supplied by the centralize generation and another part is produced by distributed generation.

The electricity is going to produced closer to the customer as shown in fig.

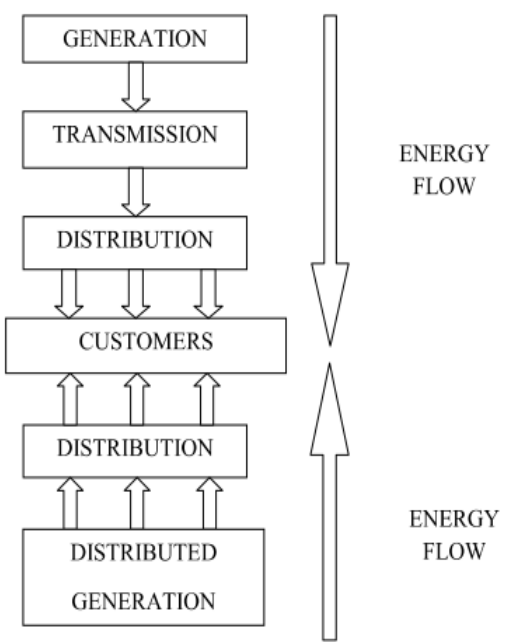

Fig-2. Model concept

\section{OVERVIEW OF GENETIC ALGORITHM}

Genetic algorithm (GAs) was invented by John Holland in 1960s and was developed with his students and colleagues at the University of Michigan. GA is a method for deriving an new population from a population of (e.g., strings of ones and zeroes, orbits).This is achieved by employing together with the genetics inspired operators of recombination (crossover), mutation, and inversion. Each chromosome consists of genes (e.g. bits), and each gene is an instance of a particular allele.The selection operator chooses those chromosomes in the population that will be allowed to reproduce, and on average those chromosomes that have a higher fitness factor (defined bellow), produce more off spring than the less fit ones.

\section{PARTICLE SWARM OPTIMIZATION}

Particle swarm optimization (PSO) is a population-based heuristic search technique, which was introduced by James Kennedy and Russell Eberhart in 1995. Its development is based on the observations of social behavior i.e. collective behavior of bird flocking, fish schooling and swarm theory, and shares many similarity. As compared to Genetic Algorithm, PSO has some attractive features or characteristics. First, PSO has memory, that is, the knowledge of good solutions is contained by all particles, whereas in GA, the previous knowledge of the problem is destroyed ones the population is changed or updated. Second, PSO has a constructive cooperation between particles, i.e. the particles in the swarm share their information among themselves. 
The particles in a PSO system fly around a multi-dimensional search space and during their flights, each particle adjust sits position according to its own experience. This position associated with its best fitness achieved so far is considered as its current best position, and is known as individual best and denoted as $\mathrm{P}_{\text {besti }}$, it is also known as personal best position. On the other hand, the global version of PSO keep strack of the overall best value $\mathrm{G}_{\text {besti, }}$, i.e. the particle adjusts itself according to the experience of a neighboring particle.

The velocity and position of each particle is updated in every iteration as per the following equation.

\section{PROBLEM FORMULATION}

Optimal placement of DG in IEEE30 bus test system is analyzed by using the optimization techniques to reduce system transmission loss while maintaining the voltage profile within the specified limit.

$$
v_{l}^{k+1}=\omega_{l} v_{l}^{k}+c_{1} \text { rand } \times\left(\text { pbest }_{l d}-s_{l}^{k}\right)+c_{2} \text { rand } \times\left(\text { gbest }_{l d}-s_{l}^{k}\right)
$$

\subsection{THE OBJECTIVE FUNCTION:-}

The objective function is the minimization of the transmission line losses, which can be

$$
\min \left(P_{\text {Loss }}\right)=\sum_{l=1}^{n l} S_{l}
$$

\subsection{CONSTRAINTS: -}

The constraints are divided into, equality and inequality constraints. The equality constraints are the real and reactive power flow equations, and, the inequality constraints include bus voltage constraints and DG technical constraint.

\section{IMPLEMENTATION OF PSO ALGORITHM FOR OPTIMAL PLACEMENT OF DG}

Step 1. Initialization of system data.Initialize the size of population and randomly create a set of complex power. Initialize the maximum number of iterations, acceleration coefficients i.e. c1, c2.

Step 2. Check the feasibility criteria

a) Ensure that the complex power should lie within the specified limits.

b) Ensure that the voltage at each bus must lie within the specified limits.

Step 3. Calculate the fitness function and evaluate personal \& global best positions.

The fitness function is calculated by using the objective function. Personal best value is the best position in its entire history for that iteration i.e. having minimum value of the particle. Global best value is the position of the particle corresponding to the minimum fitness function.

Step 4. Determination of new velocity and position.

Update the velocity of the particle and determine the new position of the particle. Final best position of the swarms is evaluated from comparing the new position of the swarm population with its initial positions and updates the iteration count.

Step 5. Stopping criteria.

Check if the desired condition is achieved otherwise repeat step 3 to step 5 .

\section{TEST SYSTEM DESCRIPTION}

IEEE 30 bus test system consists of one swing bus, five generator bus and 24 load buses and the pictorial representation of IEEE 30 bus test system is Fig

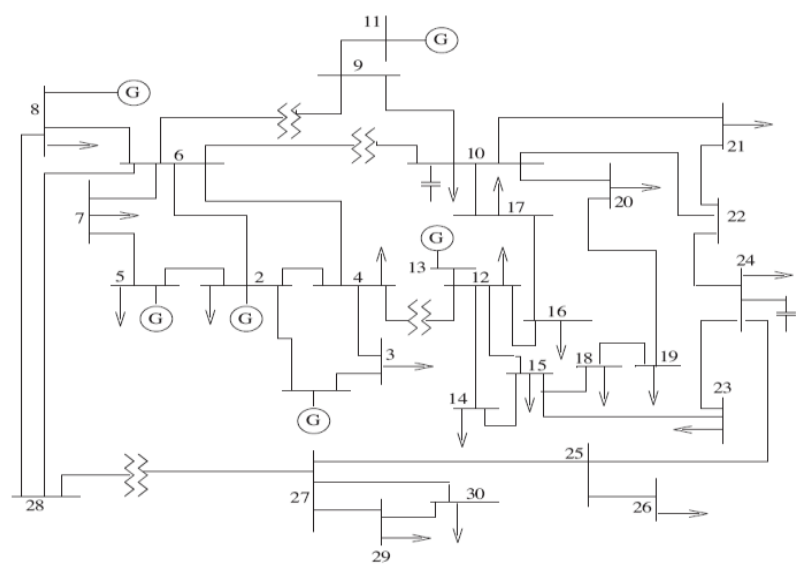


Fig 3-IEEE 30 bus tests sytems

\section{ECONOMIC LOAD DISPATCH PROBLEM USINGGENETIC ALGORITHM CASE-1 WITH NORMAL LOADING CONDITIONS:}

Table -1 - ELD for normal loading

\begin{tabular}{|l|l|l|}
\hline Sl.no. & $\begin{array}{l}\text { Bus } \\
\text { no }\end{array}$ & $\begin{array}{l}\text { Dispatched } \\
\text { power (in } \\
\text { MW) }\end{array}$ \\
\hline 1 & 1 & 172.39 \\
\hline 2 & 2 & 40 \\
\hline 3 & 5 & 32.907 \\
\hline 4 & 8 & 21.027 \\
\hline 5 & 11 & 12.12 \\
\hline 6 & 13 & 14.11 \\
\hline
\end{tabular}

The plot of fitness values of each generation is shown below:

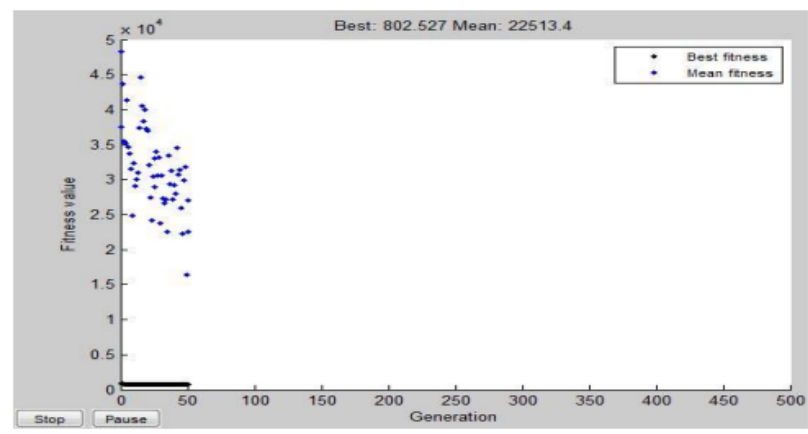

Fig 4-Fitnes value of generator

\section{CASE-2 WITH 30\% INCREASE IN LOAD:}

Table -2 - Economic dispatch using GA for $30 \%$ load increase

\begin{tabular}{|l|l|l|}
\hline Sl.no. & Bus no & Dispatched power (in MW) \\
\hline 1 & 1 & 171.59 \\
\hline 2 & 2 & 40 \\
\hline 3 & 5 & 64.98 \\
\hline 4 & 8 & 49.78 \\
\hline 5 & 11 & 9.98 \\
\hline 6 & 13 & 14.87 \\
\hline
\end{tabular}

XII. LOAD FLOW SOLUTION: WITH 30\% INCREASE IN LOAD:

\begin{tabular}{|l|l|l|l|}
\hline Bus no & Voltage (in P.U) & Bus no & Voltage (in P.U) \\
\hline 1 & 1.0600 & 16 & 1.0125 \\
\hline 2 & 1.0416 & 17 & 0.9949 \\
\hline 3 & 1.0192 & 18 & 0.9970 \\
\hline 4 & 1.0089 & 19 & 0.9911 \\
\hline 5 & 1.0025 & 20 & 1.0030 \\
\hline 6 & 1.0052 & 21 & 1.0037 \\
\hline 7 & 0.9932 & 22 & 1.0093 \\
\hline 8 & 1.0038 & 23 & 0.9954 \\
\hline 9 & 1.0343 & 24 & 0.9882 \\
\hline 10 & 1.0192 & 25 & 0.9875 \\
\hline 11 & 1.0691 & 26 & 0.9649 \\
\hline 12 & 1.0370 & 27 & 0.9981 \\
\hline 13 & 1.0539 & 28 & 1.0014 \\
\hline 14 & 1.0152 & 29 & 0.9678 \\
\hline 15 & 1.0200 & 30 & 0.9489 \\
\hline
\end{tabular}

Table -3- Solution for ELD with 30\% load increase 


\section{CONCLUSION}

In this research work, the voltage profile improvement and line loss reduction has been carried out and the following can be concluded:

1. The economic load dispatch using genetic algorithm forIEEE30 bus test system has been carried out successfully to obtain the dispatched power of each generator.

2. The low voltage bus is identified by using the Newton Raphson load flow analysis IEEE30 bus test system.

3. In order to find out the optimal placement of DG in the system, optimization techniques are incorporated with economic load dispatch using genetic algorithm and size of DG was found by particle swarm optimization technique.

4 .Benefits of installing DG had been evaluated in optimization techniques.

\section{REFERENCES}

[1] EHSANNADERI, HOSSEIN SEIFI, MOHAMMAD SADEGH SEPASIAN"A Dynamic Approach for Distribution System Planning Considering Distributed Generation” IEEE Transactions, Vol-27, no.3, July2012.

[2] M. VATANKHAH, S. M. HOSSEINI, "PSO Based Voltage Profile Improvement by Optimizing the Size and Location of DGs", International Journal on Technical and Physical Problems of Engineering, Vol-4, no. 2, pp.135-139, June, 2012.

[3] GHOLAMREZA ZAREIEGOVAR, ROYA REZVANI FESAGHANDIS, \&MOHAMMADREZA JAFARI AZAD, "Optimal DG location and sizing in distributed system to minimize losses, improve voltage stability, and voltage profile",IEEE,Conference Publications,EPDC, pp.1-6, May, 2012.

[4] HOSSAME. A. TALAAT, ESSAMAI-AMMAR, "Optimal Allocation and Sizing of Distributed on network using genetic algorithm Available limits" IEEE, Conference, EPQU, pp. 1-6,2011.

[5] S. M FARASHBASHI-ASTANCH, A.DASTFAN, "Optimal placement and sizing of DG for loss reduction, voltage profile improvement and voltage sag mitigation", International conference on renewable energy and power quality, March, 2010 .

[6] A.PARIZAD, A.KHAZALI, M.KALANTAR " Optimal Placement of Distributed Generation with Sensitivity Factor Considering Voltage Stability and Losses Indices", IEEE, Conference Proceedings, ICEE, pp.848-855, 2010 